\title{
A delineação e concretização dos conteúdos imagéticos em The Death of an Owl (2012) e No Green No Blue (2012) de Marta Alvim através de um sonoro de autor
}

\author{
Helena Maria da Silva Santana \\ INET-MD, Portugal \\ Maria do Rosário da Silva Santana \\ INET-MD, Portugal
}

\begin{abstract}
The Death of an Owl and No Green on Blue are two shorts films by Marta Alvim that directs our attention to a world read through a focus that now designs in pure, simple and strong images of a new civilizational reality, as images continues and wisely blurred that induce another reading of reality, a reading that though ours is revealed to her as Western, and a transformed world. This fact, in conjunction with the sonorous and the static and repetitive predominant music written by Filipe Lopes, design the same reality for a second level of reading, where the objects, rhythms and spaces, there are metamorphosed, by the sound that handles the conscious and the unconscious of who saw and listen the film. The sensitivity of Marta Alvim, but also the composer Filipe Lopes, proves to be central to a new reaffirmation of the film narrative and image content. Starting from an essentially makeshift base, they are able to reach the sound, that the director was looking for. Through The Death of an Owl and No Green No Blue, we can discuss how focusing techniques and blurring, as well as sequencing and handling contribute to the realization of those short films. We can still reflect on how the compositional and collaborative process can be crucial for determining the filmic, narrative and musical contents. This allows us to reflect on the process of multidisciplinary artistic collaboration in contemporary film work, including the author.
\end{abstract}

Keywords: The Death of an Owl, No Green No Blue, Collaborative Process, Marta Alvim, Filipe Lopes

\section{Introdução}

As curtas metragens The Death of an Owl (A Morte de uma Coruja, 2012) e No Green No Blue (Nem Verde, nem Azul, 2012) da autoria de Marta Alvim direcionam a nossa atenção para um mundo lido através de um foco que, ora nos projeta imagens puras, simples e fortes, de uma realidade civilizacional nova, como imagens continua e sabiamente manipuladas que nos induzem uma outra leitura do mundo e da realidade. Essa leitura, embora nossa, se mostra construída também na proposta da autora. Este fato, em conjunto com a proposta sonora de uma natureza predominante estática de Filipe Lopes, projetam o construído para um segundo nível de informação, e, consequentemente, de elaboração e leitura, onde os objetos, os ritmos e os espaços, assim como as ideias e as razões, surgem metamorfoseados por um som que afeta o consciente e o inconsciente de quem frui.
A sensibilidade da autora, mas também do compositor, revela-se fulcral para uma nova reafirmação dos conteúdos da narrativa fílmica. Partindo de uma base essencialmente improvisada, o compositor foi capaz de atingir o timbre, ou timbres, que a realizadora procurava; o discurso, ou discursos, que a autora idealizara. Neste trabalho, para além de podermos discorrer sobre como as técnicas de focagem e desfocagem, bem como sequenciação e manipulação concorrem para a realização destas curta-metragens, podemos ainda refletir sobre a maneira como o processo compositivo pode ser fulcral para a determinação dos conteúdos narrativos e musicais do filme, utilizando técnicas compositivas coincidentes com as da autora.

A componente musical, consequência de uma forte colaboração do compositor com a autora, revela características singulares. Nelas se projetam, de uma forma que podemos afirmar eficaz e consentânea, os dois autores. Neste fazer, denotamos que o dizer visual se rediz e recompõe através do sonoro e, que o sonoro, se rediz e recompõe no visual. A autora no seu dizer de imagens, e o compositor, no seu dizer de sons, captam a atenção para um mundo lido através de um foco que ora nos projeta imagens puras, simples e fortes, como nos propõe imagens que se mostram contínua e sabiamente desfocadas induzindo-nos uma outra leitura de uma mesma realidade, uma leitura que embora nossa, se revela a de Marta Alvim enquanto ocidental, uma leitura feita sobre um mundo transformado por uma aculturação proposta e aceite de um mundo, e de um autor ocidental. Em outro surge sempre a reflexão sobre a vivência, a condição e a natureza humanas. O sonho é chamado e a realidade já não é simples, transparente, ela tornase o inconsciente e a inconstância de cada um, e de todos, transportando o espetador para uma verdade ficcionada que o obriga a refletir sobre "o impacto dos valores sociais, na forma como estes alteram a noção de tempo e de espaço e o papel que cada indivíduo desempenha na sua própria vida e, consequentemente, na sociedade." (Alvim e Lopes 2015)

\section{Os Filmes - Processo criativo}

O processo criativo que Marta Alvim e Filipe Lopes encetam na produção e realização destes filmes, é um processo colaborativo e dialógico. Neste processo, "o jogo dialógico entre sujeitos não tende a uma só direção; ao contrário, envolve circunscrição, ampliação, dispersão e estabilização de sentidos. Um determinado conhecimento (pretendido, na 
intencionalidade do outro; ou previsto, na perspetiva de um observador) [se mostra]" (Góes 1997, 27). Isso significa que a confrontação e o surgimento de ideias respeitantes à construção e definição do produto artístico final, bem como o conjunto de sugestões e críticas que ao longo de todo o processo de criação se mostram, não só se tornam parte de um modus operandi próprio, como são os instigadores de um desenvolvimento material e discursivo que se complementa, tanto na individualidade das partes, como na confrontação e determinação do todo. Isto permite que o processo colaborativo se torne uma relação criativa apoiada em múltiplas interferências, uma relação em que os criadores se interpenetram para conceção de um espaço de arte conjunto e plural. Não é possível demarcar os limites estritos dessa interferência embora saibamos que, e no caso de The Death of an Owl e No Green No Blue, as interferências se tenham concretizado mais no sentido da realizadora para o compositor. Marta Alvim afirma em entrevista que o processo de construção e definição das imagens, e do discurso a elas associado estava quase fechado quando contactou o compositor (no caso particular da curta metragem No Green No Blue). Neste sentido, somos levados a pensar que a maneira como essa interferência se dá, vai depender do grau de amadurecimento do produto, do grupo, e da confiança entre os envolvidos.

Sabemos que no processo colaborativo, a interferência, é um momento extremamente delicado. Sabemos que, se na fase de confrontação de ideias o trabalho corre normalmente, o mesmo pode não acontecer quando existe interferência na criação e definição dos materiais por parte de terceiros ${ }^{1}$. Neste caso, e fruto de uma afinidade declarada pelos dois, uma fase, um processo que se exterioriza e que a maior parte das vezes surge um fator determinador e potenciador de grande tensão, mostrou-se uma fase de estreita colaboração, influenciação e respeito mútuos. Contudo, para superar e transitar com mais desenvoltura nesse momento fundamental do processo criativo, foi necessário preservar as funções de cada uma das partes. De um lado existe total liberdade de criação e interferência, mas de outro é vedado a um criador assumir as funções do outro. A responsabilidade de cada um alcança, não só a sua área específica de criação, mas também a área de criação e determinação do outro. No caso de The Death of an Owl e No Green No Blue, sabemos que o processo se deu de forma simples e eficaz, produzindo um resultado que satisfez as duas partes.

\subsection{The Death of an Owl (2012)}

Segundo o expresso pela autora,

The film/visual poem [The Death of an Ow/] is shaped as an existentialist treatise on the inflections of the human condition. It depicts the final letter from an owl who, freed from his bodily restraint, writes us from an afterlife place. By exorcising his own memories of a past earthly existence, the owl confronts and challenges us to an intimate self-projection exercise by giving us back his mental images, as if in a hall of mirrors. The Death of an Owl dwells on impermanence, the tiredness and artificialism of every days routines, relations of power, unrest and emptiness, conceived as a warning, an appeal aiming the collective conscientiousness - to a praxis that might guide us, at last, to set ourselves free from our own shackles (Alvim 2012a).

O filme The Death of an Owl revela-se, pois, uma obra importante dentro da produção fílmica da realizadora. Propõe-nos pensar o sentido da vida e da morte, bem como da condição humanas. Já no título a autora se detém no tema e nos dá a oportunidade de refletir sobre a questão. Sobre uma tela preta, o filme começa com uma referência de Friedrich Nietzsche identificando-nos a eterna questão da morte e os medos da solidão presentes na ideia de finitude e extinção. Faz referência ainda à vida e à morte de uma forma que nos leva a refletir num "modo de não-morte", porque nós devemos "live once more and innumerable times more..." (Alvim 2012b). Este é o mote para discorrer sobre a crença da vida para além da morte, bem como sobre factos que nos são propostos aquando do confronto com formas de vida em que a solidão, a indiferença e o afastamento entre os homens se encontra mais presente, resultado quiçá de uma alienação mental e social consequência de uma proposta vivencial fortemente industrializada e ligada às novas tecnologias da informação e comunicação. Além disso, a autora permite-nos refletir sobre alguns dos demónios que afluem a cada um e a todos nós, demónios esses estudados por psicólogos e psiquiatrias, crendo que se tratam, quantas vezes, de estados patológicos, de doenças físicas e mentais (0'04"):

\begin{abstract}
"What if some day or night a demon were to steal after you/ Into your loneliest loneliness and say to you:/ "This life as you now live it and have lived it, you will have to Live once more and innumerable times more...." Would you not throw yourself down and gnash your teeth/ And curse the demon who spoke thus?/ Or have you once experienced a tremendous moment/ When you would have answered him: "You are a God/ And never have I heard anything more divine."3 (Alvim 2012b).
\end{abstract}

Esta interrogação é a principal questão que se coloca quando refletimos sobre a finalidade da vida e da morte, bem como da existência humanas, assim como do significado da vida e da morte não só do homem, como de todo e qualquer ser vivo e de uma entidade suprema a que chamamos Deus. Em outro, a tela preta, o plano escuro do início do filme propõe, na nossa leitura da realidade proposta, o início, mas também o fim, da vida e da existência. No decurso da proposta fílmica de Marta Alvim, e após um período de silêncio, o sonoro inicia com um som que nos concede uma ideia de profundidade e de infinitude (0'28"). Em loop, desenvolve-se na melodia dos pássaros, um momento de esperança e vida, a vida que sempre inicia com uma morte, mas também não-morte (lembremos que é a coruja que nos fala e nos faz reviver uma 
existência). Então, a autora nos mostra um céu (0'42") um céu de um azul sublime, com matizadas nuvens que nos delineiam e enformam uma luz. O sonoro propõe a confluência dos dois opostos: o estatismo enquanto imensidão de uma escuridão morte, a melodia e harmonia dos pássaros, simbolizando a esperança e a não morte, ou seja, uma nova vida. O céu de um azul matizado pelo branco e inundado por uma luz infinita, pretendem dar ao espectador a esperança de uma possibilidade. O ponto presente na parte inferior da tela tem uma importância capital para o discurso. Estará presente no final do filme quando Marta Alvim fizer o retorno do discurso imaginário (1'03"). E o narrador diz (1'04"): "I'm sorry I haven't been in touch for so long." ${ }^{4}$ (Alvim 2012b). E continua: "I've been busy exploring a new place". "As you wished, I'm sending you my memories," "already so vague to me," "as an image from long ago"5 (Alvim 2102b).

Este conteúdo, uma presença do Divino, propõe uma vida após a morte. Pensamos que os pontos da árvore no lado direito da tela são importantes para o significado do discurso sobre o viver e o não morrer. A voz em off, origina um novo discurso e cenários onde as nuvens se dissipam e um ponto de luz se forma agora em púrpura (1'37'), originando uma nova significação da imagem. O céu, o céu que procuramos enquanto sinónimo de paz e felicidade, bem como a possibilidade de um existir em outras dimensões ${ }^{6}$ Contudo, a dúvida e a incerteza se mostram, pois, de repente, a escuridão reaparece (1'44"), como reaparecem as incertezas e as ansiedades de uma condição humanas. Alvim, depois de nos propor a esperança presente no azul de um céu e na luminosidade de uma luz, faz-nos imergir na escuridão de uma imagem negra. Contudo, a imagem de uma cidade aparece, uma imagem onde a presença de uma Catedral se faz (1'53'). E a esperança renasce, pois também renasce um símbolo e um espaço de ligação com o mais alto, Deus e o Divino, um espaço de oração e de reflexão sobre nós mesmos, no que somos, para o que estamos, num confronto entre a vida e a não morte, bem como, para onde vamos. Também a trilha sonora se modifica apresentandonos um sonoro onde uma voz sussurrando se faz presente e onde os instrumentos (cordas) se mostram, ambos com a mesma melodia, contrastando com os sons da natureza e da tranquilidade propostas no início do filme. $\mathrm{E}$ o título do filme surge sobreposto na imagem da Catedral e da cidade (2'04") ${ }^{7}$, sendo repentinamente substituída por uma imagem de écran preto (2'21") que nos conduz, uma vez mais, a um momento de introspeção. Entretanto, surge no decorrer do discurso uma imagem de um pássaro, uma coruja, (2'36"), o ator principal. Ao longo do processo de análise, perceberemos que este momento se vai revelar muito importante para a compreensão de todo o filme. No final, será a cena que reforça a mensagem de todo o texto, a ideia e um narrar proposto pela voz off, onde as imagens que fluem, e o sonoro dito, reforçam todos os significados de texto e imagem, significados que se encontram fortalecidos pelas imagens e cenas definidas pela autora. No final, constataremos a definição de uma forma em espelho produzida não apenas pela forma musical, como pelo discurso imagem. A expectativa e a tensão propostas na imagem fornecida pelo olhar da coruja em perseguição da sua caça, mostra-nos mais uma vez dois elementos contrários: o perseguidor e a presa, mas também o forte e o fraco, a possibilidade e a impossibilidade, pois que nada é eterno, tudo se mostra mutável (2'57"). E a voz reaparece: "It was a grey land, (3'01") of indefinite time. Man lived amid weakness: The weakness he induced in others, and with which he was contaminated" ${ }^{\circ}$ (Alvim 2012b). Estas palavras são essenciais para entender o sentido da vida e o significado de toda a existência humana, uma existência que se diz naquilo que fizermos aos outros e que retornará para nós como karma. O sonoro nos dá esta imagem num loop contínuo, a imagem contínua da coruja e da sua caça, mas também de uma continuidade da vida.

Depois de um tempo de reflexão em que nos deparamos com estas questões, (3'33"), a imagem transmuta novamente para um plano escuro e o som dos pássaros reaparece. É o prenúncio da transformação. A imagem de uma cidade onde surgem os seres humanos. Também uma árvore com flores, o símbolo da vida e do nascimento está lá (3'36"). E a voz (3'43"): "Foreseeing an advantage, Man had relinquished freedom in exchange for protection"9 (Alvim 2012 b). No conteúdo narrado, surge a modificação do cenário e das cenas (3'54"). Grandes planos da vida da cidade são agora incluídos: "But instead, he ended up fighting poverty, under the impossibility of choosing his own fatigue" (4'03") ${ }^{10}$ (Alvim 2012b). E a imagem de um animal numa jaula/prisão se mostra, tal como o homem se encontra numa impossibilidade de escapar ou fugir da própria vida, pois que a morte não é uma fuga, uma possibilidade. Marta Alvim mostra ainda a impossibilidade de o homem escolher o seu próprio destino, de mudar o curso da vida e das forças que o constrangem. E outra mudança de cenário é feita com uma cena escura (4'10'), e a imagem de um tigre branco e de crianças olhando (4'12"). Também as cores das vestes nos mostram a esperança de mudar e de alterar o rumo das coisas. E a voz, novamente, nos diz (4'25"): "Meanwhile life, which separates the weak from the strong, allowed Man to become the main character. And in mankind's moral challenge, which resides in the relationship that one fosters with the weaker, Man was defeated"11 (Alvim 2012b).

Aqui, a importância do plano é crucial. Antes de termos a imagem que enfoca o discurso sobre o animal, sobre a vida selvagem (4'41'), a imagem focaliza o discurso sobre o homem. Também é importante a mudança de ação (4'50") quando o homem e a menina começam a andar e vão embora, deixando a jaula. Neste dizer, um outro corte discursivo se faz pela imagem negra sobre a tela (4'57'). Também o sonoro se transforma, anunciando uma alteração de discurso: Filipe Lopes propõe-nos o som da chuva. E a voz reaparece com a sua narrativa (5'06"): "When I look back, I see that what defines mankind is the eternal quest"12 (Alvim 2012b). Aqui, o som distinto das batidas das árvores, 
o número sagrado que simboliza a perfeição (5’15”). Essas importantes missões precedem vários planos de pessoas tirando fotos de lugares turísticos da cidade (5'28'), e novamente o alerta de voz para (5'32'): "Man, a being of all possibilities, continues to search for something important"13 (Alvim 2012b). Neste ponto, um homem sobe e anda como alguém que precisa procurar algo ou ir a outro lugar. E a narração continua com a mudança constante das pessoas e a voz dizendo (5'49"): "Something he lost, or that he has never found. Man searches in the future, for what he can't find in the present"14 (Alvim 2012b). Paralelamente, uma mulher se levanta e caminha, vai embora e outro grupo de pessoas aparece. É importante ver também a mudança de personagens. Primeiro temos um homem, depois uma mulher, e em seguida uma criança. Quando estes aparecem, a voz diz (6'11"): "What, in brief, rests in the search for the meaning of his own life"15 (Alvim 2012b). Então um adolescente vem tirar uma foto (6' 29"): "Man is a creature of time that wishes to have what he doesn't know exists. And, more than what he has, it's what he lacks that makes him different from other animals" $\left(6^{\prime} 37^{\prime \prime}\right)^{16}$ (Alvim 2012b). E a imagem é centrada na criança viva, inocente e ingênua olhando para um futuro, um tempo que possibilita uma vida (6'58").

Novamente uma mudança de cenário feita pela imagem preta que surge para iluminar um novo anúncio (7'08"). A imagem do metropolitano, com as escadas de acesso às linhas e as pessoas saindo, correndo, subindo e descendo - vivências diárias na cidade. E a voz reaparece (7'13"): "However, what Man finds difficult to understand, is that while he is searching in the future, for the meaning of present, the moment is being lost"17 (Alvim 2012b). Uma nova modificação no cenário se faz: uma luz que vem de uma lâmpada no teto (7'32").

Do ponto de vista sonoro, surge um ruído, um elemento importante para intensificar o significado das palavras subsequentes (7'40"). E se a vida não repousar num instante para que o homem possa refletir sobre si (imagem negra), sua vida e seus sonhos não terão nem consistência nem substância maior que a busca de uma simples materialidade (dois homens entrando no comboio para iniciarem a jornada de olhos fechados). E assim como a matéria e a morte os privará de um futuro, o futuro os priva de um presente. E uma imagem negra aparece (8'10") quando a voz atrai a si a morte e repensa os tempos e as existências não só passado como futuro, ou seja, uma das questões fundamentais do ser humano e do sentido da existência humana.

O som que ouvimos é o som da cidade, o som do metropolitano e de uma vida cosmopolita, mas também o som do vento que nos reconduz à natureza e à presença constante de um animal em particular - a coruja. Símbolo da sabedoria, a coruja induz-nos a uma constante reflexão sobre as suas vivências ao longo da vida. Propondo-nos diferentes visões temporais, permite-nos olhar o mundo e a vida. Ao olhar o mundo e a vida, olhamos o homem e a natureza, os seus modos de ser e pensar, de fazer e dizer uma consciência. A morte da coruja, ao permitir o contacto com um outro plano existencial, mostranos que a morte não é finitude. Através das imagens narradas, consente-nos ainda uma reflexão sobre os nossos próprios modos de vida, modos que definirão o ser enquanto existência não finita. $E$ o retorno da imagem da coruja no tronco da árvore se diz (8'22) ${ }^{18}$. É o conflito entre a vida e a morte, o fim e o recomeço, a imagem da fraqueza e da força, das forças que iniciam, aniquilam e comandam a vida. $E$ a voz reaparece no seu discurso final (8'50"): "I'm sorry I haven't been in touch for so long, l've been busy exploring a new place" ${ }^{19}$ (Alvim 2012b). A coruja voa, a imagem retoma o negro, como morta, e uma obscuridade se faz (9'04"). É também o fim da forma em espelho da estrutura musical, discursiva e imagética. Contudo, um sinal de esperança é produzido pela coruja voadora, e pelo céu azul lembrando o cenário anterior (9'13"). Este, e a luz focalizada, evidenciam-nos o objetivo de toda uma existência (9'15”). O preto ressurge enquanto morte da vida anterior e possibilidade de recomeço num outro plano existencial (9'27'). A forma ABA está presente refletindo o pensamento do discurso som e imagem.

\subsection{No Green No Blue (2012)}

Segundo Marta Alvim, a segunda das curtametragens que nos propomos refletir, No Green No Blue, surge ilustrativa de várias causas que lhe despertaram a atenção aquando de uma sua visita à China. A cultura e a sociedade chinesa, opulentas e luxuriantes, encerram elementos mais trágicos que a autora quis evidenciar. Este facto vai revelarse aniquilador de um modo de vida que sempre se encontrou apoiado em valores morais e que agora se vêm amortalhados por um cânone civilizacional ocidental, que aos poucos corrompe, aniquila e destrói.

No Green No Blue de Marta Alvim inicia, à semelhança de The Death of an Owl, com uma tela escura que, no nosso entender, é uma reminiscência da presença de um ideário de morte, que, no silêncio de um sonoro se diz, e num discurso de imagens, se narra. $E$ assim, a dada altura, uma imagem sobre um fundo vermelho nos revela uma natureza (00'13") ${ }^{20}$ e o discurso surge imagem. Num seu evoluir, a imagem transforma-se em preto (00'46") e um som em piano sobrevém, numa repetição constante duma altura, depois outra, num crescendo que persegue as imagens que surgem, comentando-as (00'51"). Primeiro, um Dó, depois, um Ré, e uma voz que narra (00' 56"): "Is it real, What's on the outside?"21 (Alvim 2012c), e a repetição se realiza com recurso somente a estas duas alturas, como se de dois pés e de um caminhar se tratasse (1'12"): "After $10.000 \mathrm{~km}$ in less than 24 hours, I guess I'm still on my way"22 (Alvim 2012c). O sonoro continua estático e enfático (1'29"): "It seems that I haven't really arrived to where I am at" 23 (Alvim 2012c), até ao ponto em que, quando sobrevem a imagem de um edifício, também surge a ampliação do sonoro para três sons (1'36").

Neste momento, a consciencialização desse estatismo faz-se na realidade mostrada em tela e na sua continuação: o espaço negro. E a autora questiona: "Reality as in a screen"24 (1'45") (Alvim 2012c); "can't 
feel it"25 (1'49") (Alvim 2012c). E a tela surge preta (1'52"), por um segundo apenas, e uma nova imagem é revelada, muito mais intensa e colorida que as anteriores (1'53"). Amplia-se igualmente a escala de sons usados e outras sonoridades são incluídas. Revelam-se ainda variações melódicas e rítmicas e a voz reaparece: "I dreamed", "I was wandering on a mountain", "Trees were gently waving", "It seemed like we were underwater", "we were all in a stream" 26 (2'00") (Alvim 2012c).

Depois de um grito que ocorre numa nota aguda, a tela fica branca (2'58") e o título é revelado: "The Ingenuous passengers"27 (Alvim 2012c) (3'00"). Neste ínterim, o discurso é feito no silêncio e na mudança de cor, a mudança para um preto que se mostra novamente. A apreensão surge como revelação (3'12"), e essa emoção permanece até à imagem do mercado do peixe (3'19"). Neste momento tenso da curtametragem, Filipe Lopes propõe somente o som de água e a voz da narrativa: "Here I see some ingenuous passengers", "They are constantly being moved from one market to another", "They live conditioned in these survival containers", "Without realizing", "That something more powerful is in control"28 (3'33") (Alvim 2012c). A cena mostra um homem a organizar o peixe no mercado, um peixe que já se mostra o símbolo de uma morte anunciada. Percebemos então que este filme fala sobre a morte, mas também sobre a vida e a luta pela sobrevivência na grande cidade. Uma imagem brutal de um peixe a morrer é-nos transmitida (4'31"). Repentinamente, a tela preta reaparece (4'32"). O sonoro intensifica-se, a imagem da floresta aparece (4'39") e mais uma vez a narrativa: "I dreamed I was on a mountain"29 (4' 54") (Alvim 2012c). Contudo, as imagens subitamente (5'29"), renascendo um discurso imagem: um lago com peixes vermelhos (5'32"). E a música transforma-se para ilustrar a floresta e a vida nas montanhas, para elucidar o sonho que a autora tem e a diferença entre a vida na cidade e a vida nas montanhas. A voz revela as imagens: "There were fish in a stream"30 (5'47") (Alvim 2012c). A interpenetração das duas imagens, as montanhas e o lago com os peixes é revelada num ponto distinto da cena (6'13"), levando-nos a entender o discurso na explanação: "Everything was underwater"31 (6'24") (Alvim 2012c). E a tela preta reaparece (6'44") produzindo uma transformação bárbara no cenário. A cidade e todas as máquinas que eram necessárias para construir edifícios e estradas aparecem também (6'49"), assim como as sonoridades necessárias para ilustrar o ruído presente na cidade. $\mathrm{E}$ a voz recita novamente: "Here I see some ingenuous passengers" 32 (6'54") (Alvim 2012c) pois que este é o discurso pronunciado no mercado de peixe. Contudo, aqui a voz se refere ao ser humano (7'04"): "They are constantly being moved from one market to another"33 (Alvim 2012c). Entretanto surge a imagem de um apartamento e a voz nos informa que: "They live conditioned in these survival containers" ${ }^{34}$ (7'19") (Alvim 2012c). O mesmo discurso que é usado para os peixes no mercado: "Without realizing", "that something more powerful is in control"35 (Alvim 2012c). Depois de um ato médico que apela à reflexão sobre a vida e a morte, a tela preta aparece cortando o discurso, renovando-o (7'38"). E a voz recita: "I dreamed I was on a mountain"36 (7'47") (Alvim 2012c), e a imagem das árvores é destapada como símbolo de vida no discurso das imagens (8'03").

Aintensidade da música fortalece as imagens. O preto surge novamente (8'25") potenciando o discurso da voz: "Trees were gently waving"37 (8'27") (Alvim 2012c). E a imagem da árvore aparece ( $\left.8^{\prime} 36^{\prime \prime}\right)$, e novamente a tela preta (8'54") para revelar a voz: I thought I was underwater"38 (8'55") (Alvim 2012c). E as árvores regressam (9'03"), numa alternância de imagens que nos conduz para uma tela branca novamente (9'14"), para revelar um homem que faz Tai Chi (9'15"), até desaparecer, desvanecendo-se suavemente, para uma tela escura que revela a floresta novamente (10'21"). A imagem muda com a superposição de duas imagens diferentes de um mesmo elemento, uma na primavera e outra no inverno. A cena não contém qualquer elemento sonoro. Esta ação é intencional, pois o silêncio intensifica o significado do discurso/imagem (10'53"). $\mathrm{E}$ a imagem da cidade, a primeira imagem da cidade volta e se impõe.

Formal e discursivamente, para além de um discurso repetitivo e cíclico, sobrevêm um espelho no que concerne a forma, um espelho sobre o discurso som e imagem (10'59"). Da mesma forma, a cor dos edifícios é importante para definir o discurso. No mesmo sentido, começamos a ter o som da cidade, o som da vida que nos preenche os dias e as horas (11'08'). E a vida das montanhas desaparece (11'30") e o discurso de imagens que se baseia nos edifícios e nas lâmpadas das ruas na grande cidade permanece. A imagem e o discurso fluem para uma tela branca (11'42") revelando o início do filme não só pelas imagens, como pelo sonoro: a repetição de um som (11'52"). Um corte importante é feito (12'17'), e uma nova imagem revelada (12'18"). Temos assim, o retorno ao discurso inicial, a forma clássica, revelada também na tela preta que mais uma vez nos é mostrada (13'16"), bem como pela mudança de cenário que nos mostra novamente a imagem inicial (13'17') mas agora colorida, pois, a cor, é vida. Contudo, uma vez mais a tela preta sobrevem (13'32") para retornarmos, mais uma vez, o texto inicial: "Is it real what's on the outside?"39 (13'34") (Alvim 2012c). E a questão permanece no final do filme.

Percebemos pelos conteúdos expostos que, valores como a família, a religião e a solidariedade, surgem escamoteados numa sociedade onde a ganância material e económica impera. Fruto de uma aculturação perniciosa, a sociedade chinesa procura ocidentalizarse perdendo os seus valores e tradições. Procura igualmente o poder e a evidência, tanto política, como económica. Nesta procura revela uma opção devastadora, a opção pelo capitalismo conduzindo o povo a procurar, desenvolver e adquirir, um conjunto de meios de produção material, tecnológica e industrial que se evidenciam de uma eficiência dominadora a muitos níveis, mas, igualmente destruidora, a bastantes outros. Se, por um lado, o crescimento económico se revela numa eficiência produtiva e organizativa muito 
fortes, esse mesmo crescimento faz-se à custa de outros valores que, no nosso entender, se mostram muito mais importantes numa sociedade primeira, os valores morais e espirituais de um povo, valores esses, o suporte de uma cultura forte até então.

A produção e obtenção desses bens, fazem-se, muitas vezes, sem olhar a meios, mas unicamente a fins, fins esses que se mostram unicamente de valorização e expansão económica e material. Sem se preocupar com as consequências de tais atos, vemos uma sociedade altamente industrializada em demonstração de uma força e produtividade massivas e constantes. Nessa produção massiva, e porventura descontrolada, apuramos uma ineficácia, por parte das autoridades competentes, no controle e na gestão dos seus recursos, tanto ao nível humano, como material ou ambiental; a destruição, lobrigando desenvolver-se em um: "No Green No Blue". Nesta constatação, Marta Alvim relata, à luz do seu olhar ocidental, a vivência de um povo, a sua realização moral e material, mostrando o aniquilamento e a escravidão humanos face a uma realidade imposta por uma necessidade de realização e de consumo constantes, bem como aquela que surge e se demarca de uma falta de cuidado com a natureza e o meio ambientes, elementos e comportamentos dominantes num modo de vida que se faz destruidor.

Numa reflexão viva e perspicaz, que se traduz em uma narrativa fílmica de autor, Marta Alvim opta por utilizar a técnica da desfocagem. No seu entender, esta técnica serve para evidenciar estes factos pois na aquisição e consumo de bens provenientes deste país, a sociedade ocidental não espera, nem uma qualidade extrema, nem uma preocupação ambiental elevada. Os bens que adquirimos provenientes desse, e outros países orientais, são predominantemente de fraca qualidade. No Green No Blue, mostra-nos ainda a não existência do verde e a não existência do azul nos espaços vivenciais, sejam eles urbanos ou rurais. A não existência do verde anuncia-se na massiva utilização dos espaços verdes para construção e edificação das grandes cidades, e para a realização de uma agricultura intensiva que aniquila e destrói. A não existência do azul, o azul de um céu límpido e cristalino, um céu isento de poluição, natureza impossível de experienciar nas metrópoles altamente industrializadas, encontra-se também na vivência descrita e proposta pela autora na sua obra através do tratamento e manipulação que faz da cor (timbre), da imagem, numa fixação visual da vida e da morte. Conjuntamente, a densidade textural e timbrica da componente sonora, enfatiza os conteúdos. Sem diálogos ou personagens, os conteúdos visuais, musicais, texturais, sociais e imagéticos construídos, surgem como personagens delineando um conteúdo outro que se elucida na temática expressa imagem. A tensão e a distensão das texturas e estruturas musicais, que por vezes se revelam lineares, esquiça conteúdos de maior densidade imagética e dramática. Neste dizer, o espectador e fruidor de No Green No Blue surge emerso num sonoro que, sem o pressentir, o constrói e manipula sem cessar, um sonoro que o não permite sair, afastar-se, ausentar-se, deixar-se.

\section{Imagem e som}

A sensibilidade do compositor Filipe Lopes revelase fulcral para uma nova reafirmação dos conteúdos da narrativa fílmica e das imagens nele contidas. Partindo de uma base essencialmente improvisada, como explica em entrevista dada, o compositor foi capaz de atingir o timbre, ou timbres, a textura, ou as texturas, que a realizadora procurava, fazendo com que o filme ficasse "com uma energia particular e introspetiva cooperando de forma evidente para o propósito reflexivo do filme." (Alvim e Lopes, 2015)

Ao se despojar do acessório para expor o essencial Filipe Lopes permite, a quem frui as propostas visuais de Marta Alvim, a concretização de um espaço de expansão de si que não se encontra, no nosso entender, fechado. Quando a linguagem e o espaço de construção musical se mostram mais fechados, que não é o caso, a manipulação do fruidor é mais controlada e efetiva; se aberto, a capacidade de construção de obra, revela-se mais eficaz, efetiva, determinativa e superior.

Para além de podermos discorrer sobre como as técnicas utilizadas, nomeadamente as técnicas de focagem e desfocagem, bem como sobre a forma como a sequenciação e manipulação, tanto da componente visual como sonora concorrem para a realização de The Death of an Owl e No Green No Blue, a análise destas obras representa ainda a possibilidade de refletir sobre a maneira como o processo compositivo e colaborativo pode ser fulcral. Em outro, Marta Alvim mostra ao longo de toda a sua obra um interesse por narrativas experimentais que se constroem de forma a transmitir não só um pensamento e uma reflexão sobre um assunto ou uma questão em particular, mas, e sobretudo, como forma de transmissão de um conhecimento. Não é intenção da autora a criação e produção de narrativas lineares. Marta Alvim opta por extrapolar a significação de um qualquer conteúdo ou acontecimento em imagem, narrativa, som. A imagem surge no seu universo artístico para criar novos conceitos e pensamentos, senão outras formas de pensar. A autora afirma que é sua intenção criar elos entre o seu pensamento e o espectador. A segunda das curta-metragem, No Green No Blue, surgindo de uma viagem em residência que fez à China, tem como tema central de reflexão o Sistema Capitalista que na China surge como Capitalismo Social; a primeira, The Death of an Owl, pretende uma reflexão sobre a vida e a morte, a existência e a condição humanas ${ }^{40}$.

O som, fabricado em consequência de uma ação colaborativa com o compositor Filipe Lopes, exalta uma forma de expressão, um dizer artístico, onírico. Neles, suspende e empreende uma ação dinamizadora de um inconsciente reflexivo sobre a proposta das imagens. Para que assim fosse, Marta Alvim procurou um autor que entendesse esta sua ação. Simultaneamente, o compositor depara-se com um objeto, nalguns casos, quase fechado. A realizadora fornece-lhe um conjunto de linhas orientadoras que analisa de forma a descobrir um universo comum. Depois de descobertos esses universos, esse "DNA" como 
afirma o compositor (Alvim e Lopes 2015), o autor passa ao processo compositivo mais convencional e, por isso, formal. Opta por sons eletrónicos e por processos de desfocagem à semelhança da autora. Opta por estruturas contínuas, minimais e repetitivas, de maneira a permitir a captação e construção de um terceiro nível discursivo por parte de quem fruiu. Neste fazer, e em particular em relação à curta-metragem No Green No Blue, Filipe Lopes afirma que o processo foi sobremaneira colaborativo, sendo que os autores foram desenhando e reafirmando, aos poucos, e de forma conjunta, a narrativa do som e da imagem (Alvim e Lopes 2015). As palavras do compositor revelam ainda a importância de associar a criação musical com a imagem, fornecendo uma congruência diegética no objeto proposto. O compositor, procurando a perfeição da forma emotiva e sensorial da componente sonora, visa o diálogo com a imagem, estimulando de forma continuada a mente do espectador. Deste modo, os elementos não diegéticos são explorados, fora do ecrã, para atingir uma comunicação emocional consistente com toda a narrativa. Filipe Lopes procurou reafirmar os conteúdos da imagem e os processos reflexivos que dela emanam, aceitando a proposta da autora.

\section{Conclusão}

Por vezes, podemos ser levados a pensar que obras de arte deste género, obras de arte onde o processo colaborativo impera, independentemente de estas se encontrarem adstritas ao cinema, ao teatro, à literatura ou à música, são obras que evoluem anarquicamente no tempo, mas isso não é verdade. Esta tipologia de obras obedece a leis rigorosas de estruturação e definição discursivas, sem as quais não seria possivel obter uma ordem, um rigor que impede o desmoronar de um pensamento, de uma escolha consciente, de um objetivo final. $O$ resultado não seria positivo se as partes, de forma individual, não resultassem na forma do todo, assim como o todo, não resultaria, se as partes não se complementassem de forma hábil e sábia. Em outro, contribuindo para a obtenção de uma obra distinta, a sucessão de diversas situações vivenciais e comunicacionais, diferentes formas de abordar uma mesma problemática, concorre nas diferentes formas de expressão das curtas metragens expostas - The Death of an Owl e No Green No Blue -, como elemento gerador de cultura, de espaços, de emoções, de arte, como elemento gerador de uma nova forma de dizer o homem, a vida e a morte, o verde e o azul, a consciência e existência humanas. Do ponto de vista formal e narrativo, a forma em arco, uma estrutura ABA, bem como a apresentação cíclica e repetitiva de elementos, contribui para a definição da forma discursiva enformada das obras.

No enunciar de Marta Alvim, e no caso particular da curta metragem No Grren No Blue, a obra não foi uma coisa muito pensada, foi uma coisa muito instintiva. No seu dizer, uma harmonia entre si e o compositor permitiu um enriquecimento mútuo e da narrativa fílmica. O uso das técnicas de focagem e desfocagem, tanto ao nível do som como da imagem, permitiu uma coerência e uma conexão entre os dois universos criativos que se manifesta coerente e eficaz. O dizer da autora, na constante focagem e desfocagem de conteúdos, no constante imergir e emergir de sentidos e dizeres, traduz-se no sonoro em processos de modelação e modulação contínua do espaço sonoro tanto ao nível das frequências como dos timbres, bem como ao nível do uso e manipulação e aplicação constantes das técnicas de fade-in e fade-out que o compositor usa de forma continuada nos diferentes niveis de construção e estratificação discursivos. Estas técnicas continuamente empregues pelo compositor de forma a gerar, estender e manipular o seu sonoro, geram um sonoro igualmente de autor.

Para além de podermos discorrer através de The Death of an Owl e No Green No Blue sobre a maneira como as técnicas de focagem e desfocagem se encontram presentes tanto ao nível da narrativa das imagens como do discurso sonoro, podemos, através destas obras, refletir sobre a forma como os dois autores sequenciam e manipulam os materiais e os discursos de forma a dizer Nem Verde, Nem Azul, mas também Vida e Morte, Espírito e Ressurreição. Os dois autores surgem potenciadores de uma realidade física, social e material que se projeta aniquiladora de dois elementos fundamentais ao equilíbrio e sobrevivência humanos - o meio ambiente (o verde), e o equilíbrio, a paz e a tranquilidade (o azul), mas também os reinos animal (homem, peixes, aves) e vegetal (lagos, mares, parques e florestas), do mundo em que habitamos, enfim. Meditar sobre a maneira como o processo compositivo e colaborativo pode ser fulcral para a determinação dos conteúdos fílmicos, narrativos e musicais do objeto artístico resultante surge um desafio: o sonoro pode concretizar-se, o discurso imagem estabilizar na sua narrativa final, uma narrativa reerguida pelo som, uma narrativa que se extrapola no interior do som e no imaginário que dele se desvela, contribuindo para um outro conhecimento do mundo que nos cerca.

Sabendo que nem sempre é possível um trabalho que se diz colaborativo, analisar dois filmes onde este processo se concretizou, torna-se, no nosso entender, uma mais-valia para nós enquanto investigadores. Podemos não só refletir num espaço de arte concreto sobre a interação e influenciação mútuas no processo de criação, como examinar se o processo de colaboração artística se mostra delineador de conteúdos imagéticos e musicais eficazes na emancipação do objeto arte. Permite-nos ainda verificar se se faz essencial na determinação dos conteúdos funcionais e, sobretudo valorativos e morais, das duas propostas: The Death of an Owl e No Green No Blue. No nosso entender, sim.

\section{Notas Finais}

${ }^{1}$ No caso de The Death of an Owl e No Green No Blue o material produzido pelo compositor foi examinado e aprovado pela realizadora, processo esse que não se manifestou constrangedor para Filipe Lopes.

2 "viver uma vez mais e inumeráveis vezes mais...". As traduções aqui propostas são da responsabilidade das autoras. 
3 "E se algum dia ou noite um demónio fosse roubar depois de você/ Em sua solidão mais solitária e diga a você:/ "Esta vida como você agora vive e viveu, você terá que/Viva uma vez mais e inúmeras vezes mais..." Você não se jogaria para baixo e rangeria seus dentes? / E amaldiçoar o demónio que falou assim? / Ou você já experimentou um tremendo momento/ Quando você lhe teria respondido: "Você é um Deus/ E nunca ouvi nada mais divino".

4 "Sinto muito por não ter mantido em contacto faz algum tempo."

5 "Estou ocupado explorando um novo lugar". "Como foi seu desejo, estou enviando minhas memórias", "já tão vagas para mim", "como uma imagem de muito tempo atrás".

${ }^{6}$ Devemos fazer referência ao fato de que o ponto da árvore que mencionamos antes desaparece nesse ponto do filme e o roxo/purpura está, neste momento, muito presente (1'43 ").

${ }^{7}$ Podemos ver aqui uma sombra do filme inteiro.

8 "Era uma terra cinza, (3'01") de tempo indefinido. O homem vivia no meio da sua fraqueza: a fraqueza que induzia nos outros, e com a qual estava contaminado".

9 "Prevendo uma vantagem, o Homem renunciara à liberdade em troca de proteção".

10 "Mas ao invés disso, ele acabou lutando contra a pobreza, sob a impossibilidade de escolher sua própria fadiga".

11 "Enquanto isso, a vida, que separa os fracos dos fortes, permitiu que o Homem se tornasse o personagem principal. E no desafio moral da humanidade, que reside na relação que se promove com o mais fraco, o homem foi derrotado".

12 "Quando olho para trás, vejo que o que define a humanidade é a eterna busca".

13 "O homem, um ser onde podemos encontrar todas as possibilidades, continua a procura, uma procura por algo importante".

14 "Algo que ele perdeu, ou que ele nunca encontrou. $\mathrm{O}$ homem procura no futuro, pelo que não consegue encontrar no presente".

${ }^{15} \mathrm{O}$ que, em resumo, repousa na busca pelo significado de sua própria vida".

16 "O homem é uma criatura do tempo, uma criatura que deseja ter o que sabe que não existe. $\mathrm{E}$, mais do que ele tem, é no desejar o que não possui, o que o diferencia de outros animais".

17 "No entanto, o que o Homem acha difícil de entender, é que enquanto ele está procurando no futuro, pelo significado do presente, o momento está sendo perdido".

${ }^{18}$ Devemos referir que este é o ponto de retorno, o mesmo cenário e o mesmo som do início do filme (2'36"). O sonoro tem a mesma energia e o modo como a coruja procura a caça também.

19 "Desculpe-me, não tenho entrado em contato faz já bastante tempo, tenho estado ocupado explorando um novo lugar".

${ }^{20} \mathrm{Em}$ The Death of an Owl, a ação se faz sobre um fundo azul.

21 "É real, O que está do lado de fora?"

22 "Depois de $10.000 \mathrm{~km}$ em menos de 24 horas, acho que ainda estou a caminho".

23 "Parece que não cheguei realmente onde estou".

24 "Realidade como numa tela".

25 "não pode senti-lo".

26 "Sonhei", "Imaginei-me numa montanha", "Árvores balançavam suavemente", "Parecia que estávamos debaixo d'água", "estávamos todos num sulco".

27 "Os passageiros ingénuos".

28 "Vejo alguns passageiros ingênuos", "São deslocados constantemente de um mercado para outro", "Vivem acondicionados em contentores de sobrevivência", "Sem perceber", "Que algo mais poderoso os controla".

29 "Sonhei que estava numa montanha".

30 "Havia peixes num riacho".

31 "Tudo estava debaixo d'água".

32 "Vejo alguns passageiros ingénuos".

${ }_{33}$ "São constantemente deslocados de um mercado para outro".
34 "Vivem acondicionados nestes recipientes de

sobrevivência".

35 "Sem perceber", "que algo mais poderoso os controla".

36 "Sonhei que estava numa montanha".

37 "As árvores balançavam suavemente".

38 "Pensei que estava debaixo d'água".

39 "É real o que está do lado de fora?"

${ }^{40}$ Ao longo da sua permanência na China a autora verificou que esta designação surge como subterfúgio a uma ideologia e a um modo de vida que privilegia o consumo e a ascensão social, valores ocidentais e não orientais. Este facto tem, no dizer da autora, repercussões morais e éticas enormes, nomeadamente ao nível de uma visão nocional e uma atitude consumista daquilo que elegemos como meio ambiente, e sobre o futuro, tanto da sociedade, do homem em particular, do nosso planeta. A natureza humana espelhada em No Green No Blue, denotam essa mesma ambição, bem como a prisão humana que fluiu dessa atitude vivencial e moral. No Green No Blue surge como um declarado manifesto em defesa dos princípios da vida.

\section{Bibliografia}

Alvim, M. 2012a. The Dead of an Owl. http:// martaalvim.com/index.php/film/the-death-of-anowl\#prettyphoto[tdoao]/3/. Acedido em 3 de janeiro de 2019.

Alvim, M. e Lopes, F. 2015. Entrevista com os autores. (entrevista realizada por no âmbito da realização de um trabalho académico em Novembro 2015)

Goés, M. C. R. As relações intersubjetivas na construção de conhecimentos. In: Goés, M. C. R. e Smolka, A. L. B. Org. 1997. A significação nos espaços educacionais: interação social e subjetivação. Campinas: Papirus.

\section{Filmografia}

No Green No Blue. 2012c. De Marta Alvim. Portugal: https://vimeo.com/93097416. Acedido em 15 de janeiro de 2016.

The Dead of an Owl. 2012b. De Marta Alvim. Portugal: https://vimeo.com/90452338. Acedido a 23 março de 2017. 